\title{
Terminology for radiographic projections
}

Sir,

Dr Grainger (Br Heart $\mathcal{f}$ 1981; 45: 109-11) recommends for standard use two conventions for terminology to describe radiographic projections for cardiological investigation.

Convention $I$ is where the radiographic projection is labelled by the name of that part of the body next to the imaging device and gives rise to the terminology for oblique views, for example left anterior oblique.

Convention II is where the radiographic projection is identified by the direction of the $x$-ray beam, for example posteroanterior, craniocaudal.

It seems unnecessary to use two conventions when describing one view; one would do perfectly well. Using Convention I only, typical views would be left anterior cranial oblique, right anterior caudal oblique, etc. Using Convention II only to describe such views, the terminology would be right-left, posteroanterior, caudocranial oblique, and left-right, posteroanterior, craniocaudal oblique. Dr Grainger recommends a mixture, for example left anterior oblique, caudocranial. While not in any way condoning misuse of the terms craniocaudal, or cranial tilt, I submit that projections described using Convention I only unambiguously describe the view in question and apply equally well to installations which have the image intensifier mounted below the table, rendering it unnecessary to specify the relation of the equipment to the patient. For example, if it is already understood that left anterior oblique gives approximately the same image as right posterior oblique, so does left anterior cranial oblique resemble right posterior caudal oblique. The projections are simple and not complex as is claimed: it is only when two conventions are muddled together that the complexity emerges.

May I, Sir, submit this simpler proposition for general use.

Simon Rees,

National Heart Hospital,

Westmoreland Street,

London W1M 8BA.

This letter was shown to Dr Grainger who replies as follows:
Sir,

Thank you for permitting me to respond to $\mathrm{Dr}$ Rees's comments. It is gratifying that an experienced cardiac radiologist accepts the two internationally agreed, long established conventions for describing radiographic projections. Dr Rees, however, protests at the application of Convention II (that is specifying the direction of the $x$-ray beam) in describing the axial tilts used in cardiac radiology.

The standard radiograph of the chest is generally described as the "posteroanterior" projection (Convention II), yet Dr Rees seems to prefer "anterior". A request for an "anterior" chest projection, would probably cause confusion, some interpreting it as a request for a posteroanterior projection, others for an anteroposterior projection. My suggestion for using Convention II for describing axial tilts is merely the logical extension of the universally accepted description of the conventional chest radiograph as "posteroanterior".

The use of unqualified terms such as "cranial" as Dr Rees suggests does not indicate whether the $x$-ray tube, the imaging device, or the anatomical part is being described as "cranial". Nor does it indicate whether the equipment is moved (shifted) in a cranial direction or whether it is tilted towards the cranium. Each of these alternatives results in different projections and different radiological images.

Compound cardiac radiographic projections involve rotation of the $x$-ray beam both in the transverse body plane and in the sagittal longitudinal axis of the body. Despite Dr Rees's comment, these projections and their terminology certainly cause confusion, particularly to personnel without formal radiographic training.

Using only Convention II to describe these projections results in the tongue-twisters in the fourth paragraph of Dr. Rees's letter, and these are best avoided. Experience has shown that the use of both Conventions I and II to describe compound projections, for example "left anterior oblique, caudocranial" projection, is much less liable to misinterpretation than "left anterior oblique, cranial" which Dr Rees suggests. The addition of the word "caudal" indicates that a tube tilt and not a tube shift 
is being described, and it also indicates the direction of the $x$-ray beam.

Surely the addition of one extra word is justified to clarify a potentially confusing situation, particularly between different departments and in the international publications.
Ronald G Grainger,

$X$-Ray Department,

Royal Hallamshire Hospital

and Northern General Hospital,

Sheffield S10 2JF.

\section{Notices}

Br Heart $\mathcal{F} 1981$; 46: 588

Subacute bacterial endocarditis

A survey is currently being carried out by the British Cardiac Society and the Medical Services Study Group of the Royal College of Physicians. Though improvement of dental prophylaxis is the prime objective, the survey is already yielding other valuable information. It is hoped that proformas will be received in respect of a high proportion of patients with subacute bacterial endocarditis in the British Isles seen during 1981 and 1982 and readers are asked to arrange for them to be submitted in respect of any cases that some to their notice. Proformas can be obtained from Sir Cyril Clarke, Medical Services Study Group, King's Fund Centre, 126 Albert Street, London NW1 7NF (tel. 01-267 6111, ext. 263) to whom they should be returned.
Les Journées Internationales de Cardiologie de Paris auront lieu les lundi 17, mardi 18, et mercredi 19 Mai 1982 à la Faculté de Médecine Pitié Salpêtrière, 105 Bd de l'Hôpital, 75013 Paris.

Pour tous renseignements concernant le programme et les inscriptions s'adresser à $\mathrm{Mr}$ le Professeur Grogogeat, Service de Cardiologie de la Salpêtrière, 47 Bd de l'Hôpital, 75013 Paris, France. 